\title{
REPORT OF THE NEW FNGLAND ASSOCIATION OF CHEMISTRY TEACHERS.
}

The thirty-ninth meeting of the association was held Saturday, October 22, 1910, at Boston University, Boston, Mass. After the reading of the annual reports of the secretary and the treasurer, the report of the committee on current events was read by title to be published in the printed report of the meeting. Mr. George Cowen review ed Mr. R. P. Williams's "Fssentials of Chemistry," and Mr. W. Segerblom reviewed the "Chemist's Pocket ManuaI," by R. K. Meade.

The opening address was by Professor H. W. Morse of Harvard University on "The Experimental Basis of the 'Theory of Radio-activity." He reviewed the work of Rutherford, Soddy, and the Curies, and discussed relations between the decomposition of radium emanations, the passing of an electric current through a gas; and the absorption spectra at low temperatures. Mr. Walter G. Whitman of the Salem Normal School described some interesting new experiments on the analysis of respired air, the percentage of carbon monoxide in illuminating gas, and the combustion of iron in oxygen. The last address of the session was given by Professor Latham Clark of Harvard University on "Some Phases of the German Chemical Industry." His extremely interesting and eye-opening talk dealt with the economical production of carbon dioxide with the greatest saving of material and energy, using this as an example of the German method of utilizing waste.

An impressive part of the business session was the recognition of the recent death of two of the members of the association, Miss M. G. Farwell, and Mr. L. O. Towne. On motion from the floor the members of the association paid their respects to the memory of these two members by raising and standing silent a few moments.

It was voted to incorporate the association under the laws of the state of Massachusetts; also to establish a committee authorized to receive and care for text-books, specimens, and other illustrative material that may be donated for the use of the association. The following officers were elected for the ensuing year: President, Mr. F. C. Adams; Vice-President, Mr. O. W. Goodrich ; Secretary, Mr. E. S. Bryant; Treasurer, Mr. A. M. Butłer; Lxecutive Committee: Professor F. L. Bardwell, Mr. H. Bisbee, and Mr. G. A. Cowen. The meeting adjourned at twelve-thirty.

WHHELM SegerbLom.

\section{KANSAS ASSOCIATION OF MATHEMATICS TFACHERS.}

The Kansas Association of Mathematics Teachers held their annual meeting in the audience room of the Baptist Church, Friday, October 21, at 2 P. M., the president, Mr. A. M. Bogle of Kansas City, presiding.

The central thought, "What to Emphasize and What to Eliminate in High School Mathematics," was carried out in the following program:

"Geometry, from the Standpoint of the High School," by Miss Eleanora Harris of Hutchinson, who said in part: "One prominent reason for trouble in geometry is that the teacher does not use good judgment at the beginning; makes the subject too hard or too easy to attract." Among the things to emphasize she advised correlation, accurate construction, many originals and many numerical problems; loci problems, historical facts and free use of oral work, models, and diagrams. Among the things to eliminate she suggested problems or proofs too difficult for the class, too strict adherence to logical order, incommensurable cases, and all but a cursory treatment of limits. 


\section{SHOP}

\section{PROBLEMS IN MATHEMATICS}

The first book to emphasize properly the important relation of Mathematics to Manual Training. Price, $\$ 1.00$.

THE problems of this book are practical applications of the processes of mathematics to the regular work of the manual training shop. Through them students may obtain a double drill which will strengthen their mathematical ability and facilitate their shop work. Clear explanations of the mechanical terms common to shop work, illustrations of the machinery and tools referred to in the text, and hints as to short methods make the book an easy one for both student and teacher to handle.

\section{GINN AND COMPANY, PUBLISHERS}

BOSTON

NEW YORK

CHICAGO

LONDON

\section{Three Books Every Nature Lover SHOULD HAVE}

APGAR'S TREES OF THE NORTHERN UNITED STATES (Their Study, Description and Determination). Cloth, 12mo. 224 Pages. Illustrated. Price, $\$ 1.00$.

APGAR'S BIRDS OF THE UNITED STATES, East of the Rocky Mountains. A Mantual for the Identification of Species. Cloth, 12mo. 414 Pages. Illustrated. Price, $\$ 2.00$.

APGAR'S ORNAMENTAL SHRUBS OF THE UNITED STATES

Cloth, 12 mo. 352 pages. Illustrated. Price, $\$ 1.50$.

\section{AMERICAN BOOK COMPANY NEW YORK


Following this, J. W. Young of the University of Kansas spoke on the same subject from the standpoint of the university. He advised teachers to emphasize whatever leads pupils to think, pointing out that one can get information without thinking, but cannot think without information. Allow pupils to think in their own way if necessary, not insisting on strictly formal proofs. Among the causes of poorly prepared students are the text-book and the artificial formal demonstration. Mr. Young emphasized the desirability of the early introduction of functionality both in algebra and geometry.

In the discussion following these two papers it was found that many think the theorem should be committed to memory, while others think only substance need be learned. Some thought even definitions need not be learned.

Professor E. R. Hedrick of the University of Missouri then gave an address on "Selection of Topics for Elementary Algebra," in which he said that nothing need be taught in algebra that could not be justified in itselfif given only for help in , something else, it might be omitted. Problem solving is justified in itself only if applied to problems that need solving. The study of variable quantity and the acquisition of power to control or know variable quantity resulting in the habit of functional thinking, is the real reason for studying algebra. Formal manipulation, such as cube root, difficult square root, hard fractions, radicals, and long division, have no place in elementary algebra. Summing up Mr. Hedrick said: "The life of algebra is variability; the spirit dependence of one quantity on another, and the tools, algebraic relations stated in symbols."

Miss Ella Woodyard of Kansas City, Kan., then told of "An Experiment in Rearranging the Order of Topics in First Year Algebra," which was very interesting and is proving a successful plan.

The nominating committee reported for offcers for the ensuing year: President, Professor C. H. Ashton, University of Kansas; for SecretaryTreasurer, Miss Eleanora Harris, Hutchinson, Kan.

Eмma Hrde, Secretary-Treasurer.

\section{THE VOLATILE MATTER OF COAL.}

This is the title of the first bulletin to be issued by the new Federal Bureau of Mines. The authors, Horace C. Porter and F. K. Ovitz, conducted their investigations at the Pittsburg station while it was under the Technologic Branch of the Geological Survey, the work being a continuation of the fuel investigations begun several years ago at the Louisiana Purchase Exposition, St. Louis, Mo. The results obtained at that plant showed that the work of determining the fuel values of the coals and lignites in the United States with a view to increasing efficiency in their utilization would be incomplete if it did not include systematic physical and chemical researches into the processes of combustion. Hence in their later investigations the authors carried on such researches, concentrating attention on those lines of inquiry which promised results of greatest economic importance. This bulletin is therefore a report on an investigation of the volatile matter in several typical coals-its composition and amount at different temperatures of volatilization.

Quoted directly the authors say: "The investigation has already shown that the volatile content of different coals differs greatly in character. The volatile matter of the younger coals found in the West includes a large proportion of carbon dioxide, carbon monoxide, and water, and a correspondingly small proportion of hydrocarbons and tarry vapors. The older bituminous coals of the Appalachian region yield volatile matter containing large amounts of tarry vapors and hydrocarbons, difficult to burn completely 